\title{
A AULA-OFICINA COMO CAMPO METODOLÓGICO PARA A FORMAÇÃO DE PROFESSORES EM HISTÓRIA: UM ESTUDO SOBRE O PIBID/HISTÓRIA/ UEL ${ }^{1}$
}

\author{
CLASSROOM-WORKSHOP AS A METHODOLOGICAL FIELD FOR TEACHING \\ EDUCATION IN HISTORY: A STUDY ABOUT THE PIBID/ HISTORY/ UEL
}

\author{
Marlene Rosa Cainelli ${ }^{2}$ \\ Elizabete Cristina de Souza Tomazini ${ }^{3}$
}

\begin{abstract}
RESUMO: Nossa investigação foi realizada a partir de relatórios e entrevistas com pibidianos que atuaram nos anos de 2011 e 2012 no curso de História da Universidade Estadual de Londrina. Os pibidianos revelaram como acreditavam na possibilidade de exercer a docência a partir dos pressupostos da Educação Histórica, em especial, o modelo de aula-oficina. Neste artigo apresentamos as discussões sobre a utilização da aula-oficina nas experiências do PIBID, e, posteriormente, em sala de aula a partir das entrevistas realizadas com os pibidianos que agora são professores da educação básica. Pesquisadores deste campo teórico, como Barca $(2001 ; 2011)$, defendem que devemos ter um olhar atento sobre a formação inicial ofertada aos graduandos. Este artigo procura trazer contribuições para as reflexões sobre a formação inicial de professores de História, no sentido de entender que é necessário integrar os conhecimentos teóricos e práticos nos currículos dos cursos de licenciatura.
\end{abstract}

Palavras-chave: Educação Histórica. Aula-oficina. Formação de professores. PIBID.

\footnotetext{
ABSTRACT: Our research was conducted through reports and interviews with "pibidianos" who participated in the PIBID project from 2011 to 2012 in the History course from the State University of Londrina (UEL). The "pibidianos" revealed how they believed in the possibility to teach based on the assumptions from History Education, especially the model of classroom-workshop. In this article, we present discussions about using classroom-workshop in the PIBID experiences and, afterwards, in classroom, based on the interviews with the "pibidianos", who are currently teachers from basic education. Researchers from this theoretical field, such as Barca $(2001 ; 2011)$ argue that we must have a careful look at the initial training offered to undergraduate students. This article aims to bring contributions for the reflections about the initial training of History

1 Este artigo faz parte da dissertação de Mestrado em Educação defendida em 2017 pela Universidade Estadual de Londrina que teve como objetivo central analisar a participação de licenciandos do curso de História desta universidade, no Programa Institucional de Bolsa de Iniciação à Docência (PIBID), financiado pela Coordenação do Aperfeiçoamento do Pessoal do Ensino Superior (CAPES) e as possíveis apropriações por esses sujeitos sobre os pressupostos da Educação Histórica no que se refere ao ensino de História.

2 Universidade Estadual de Londrina. Doutora em História pela Universidade Federal do Paraná.

3 Professora da Secretaria de Estado da Educação do Paraná. Mestre em Educação pela Universidade Estadual de Londrina.
} 
teachers, in the sense of understanding that it is necessary to incorporate the theoretical and practical knowledge in the curriculums of licentiate courses.

Keywords: History Education. Classroom-workshop. Teacher education. PIBID.

\section{Introdução}

Segundo Barca (2012, p. 37), a "Educação histórica tem a preocupação em contribuir para aquilo que, talvez, falte ainda no panorama global dos trabalhos em Ensino da História (e de alguns outros saberes): ligar a teoria à prática", com isso, seu maior desafio é superar a ideia de que é possível ensinar a partir de propostas prescritivas não testadas em estudos empíricos. Para a pesquisadora, a formação em ensino de História deveria ser realizada a partir de "situações de aprendizagem reais, em contextos concretos" o que possibilitaria "disseminar resultados que poderiam ser ajustados a outros ambientes educativos".

Barca (2012, p. 38) aponta indícios de que o contato com esse campo teórico desperta em "muitos dos professores no ensino fundamental e médio" o desejo de seguir "com entusiasmo por estes caminhos, percebendo que isso possibilita a construção de aulas que oportunizam aos alunos a formação de um pensamento histórico genuíno". Por isso, a escolha do campo teórico que sustenta as atividades do subprojeto do PIBID ${ }^{4}$ História UEL (2011-2013) foi a Educação Histórica, pois na opinião dos coordenadores possibilita a criação de novas possibilidades para um ensino de História diferenciado. A Educação Histórica permite que os professores tenham um olhar de investigador e, nesse sentido, privilegia as concepções dos agentes diretos da aprendizagem e do ensino deixando em segundo plano os documentos mais ou menos prescritivos

4 PIBID é um Programa de Iniciação à Docência. Segundo a página da Capes que financia o projeto "O Pibid é uma iniciativa para o aperfeiçoamento e a valorização da formação de professores para a educação básica. O programa concede bolsas a alunos de licenciatura participantes de projetos de iniciação à docência desenvolvidos por Instituições de Educação Superior (IES) em parceria com escolas de educação básica da rede pública de ensino. Os projetos devem promover a inserção dos estudantes no contexto das escolas públicas desde o início da sua formação acadêmica para que desenvolvam atividades didático-pedagógicas sob orientação de um docente da licenciatura e de um professor da escola". Na Universidade Estadual de Londrina 14 licenciaturas desenvolvem o programa de Iniciação à docência. Na licenciatura em História o programa é desenvolvido desde 2011 e hoje conta com 60 bolsistas de iniciação à docência, 8 supervisores (professores de História da educação básica) e três coordenadores de área que são professores do departamento de História. 
com que os agentes principais trabalham em situação de aula: alunos, professores, manuais, currículo. (BARCA, 2011, p. 25).

Segundo Lee (2006), nesta perspectiva, alunos e professores se tornam protagonistas das pesquisas e das ações que resultam na atividade empreendida. Baseada em estudos realizados, desde a década de 1970, na Inglaterra, EUA, Canadá, Portugal e no Brasil, a Educação Histórica investiga como se desenvolve o pensamento histórico dos estudantes e professores, superando as ideias de que haveria estágios de aprendizagem. Ela considera que o conhecimento é construído a partir do acesso as fontes e documentos. Assim, Barca (2004a) estabelece que para ser competente em História, segundo os preceitos da Educação Histórica, é preciso:

- Saber "ler" fontes históricas diversas, a vários níveis - com mensagens diversas e com formatos também diversos.

- Saber confrontar as fontes nas suas mensagens, nas suas intenções, na sua validade.

- Saber selecionar as fontes, para confirmação e refutação de hipóteses descritivas e explicativas.

- Saber entender- ou procurar entender

- O "Nós" e os "Outros", nos seus sonhos e angustias, nas suas grandezas e misérias, em diferentes tempos, diferentes espaços.

- Saber Levantar novas questões, novas hipóteses a investigar.

- O que constitui, afinal, a essência da progressão do conhecimento. (BARCA, 2004a, p. 134-135).

As pesquisas realizadas destacam que a grande contribuição ao pensar o ensino de História a partir desta teoria é a perspectiva do [...] "poder" (empowerment) às pessoas, ao criar gente livre, com ideias próprias e atentas ao que se passa a sua volta em vez de "cidadãos-robôs", muito competentes tecnicamente, mas que pensam o que a mídia (e outros poderes) Ihes "propõem" pensar (CAINELLI; SCHMIDT, 2011, p. 40). Barca (2001, p. 14) ressalta que para aprendizagem ocorrer é preciso refletir, também, sobre a formação em Ensino de História, não podendo ser ignoradas as práticas dela decorrentes. Nesse sentido, é necessário observar, com mais atenção, a formação ofertada aos professores de História da Educação Básica, pois deveria focar no fortalecimento da progressão dos conhecimentos históricos que os alunos apresentam, em detrimento da reprodução das convenções quantitativas e conteudistas. Contudo, 
isso só ocorreria se os professores tivessem clareza sobre como atuar dentro destas novas perspectivas, por isso destaca que:

1-Será útil que os professores experienciem a pesquisa histórica e, com base nela, aprofundem o debate em torno de conceitos inerentes ao saber histórico.

2-O contacto com os resultados recentes da investigação sobre o pensamento histórico de alunos e professores torna-se igualmente imprescindível. Estes resultados poderão fornecer elemento para a elaboração de materiais criteriosos e aplicar um ensino de História com qualidade. (BARCA, 2001, p. 21).

Assim, o conhecimento não se entende mais como um mero produto de descobertas espontâneas, nem algo transmitido mecanicamente pelo meio exterior, ou pelo professor, mas o "[...] resultado de uma interação com o meio físico, social e simbólico, na qual o sujeito é sempre um elemento ativo, que procura compreender o mundo e resolver as interrogações que este mundo provoca" (CAIMI, 2007, p. 26).

Schmidt e Garcia (2006, p. 16) afirmam que a partir da década de 1980 "as pesquisas sobre ensino de História cresceram gradativamente no Brasil" e uma das questões que despontou foi a necessidade de "melhorar a formação dos mestres e profissionalizar o ofício de professor, desenvolvendo pesquisas que construíssem um repertório de conhecimentos específicos sobre ensino[...]". Segundo essas autoras,

As dissonâncias entre as demandas do desenvolvimento econômico capitalista e as respostas educacionais foram sendo reveladas em vários relatórios e estudos publicados na década de oitenta, os quais apontaram uma "grande crise" na educação, particularmente nos países americanos. Em grande parte, esta crise foi creditada ao péssimo preparo dos professores (SCHMIDT; GARCIA, 2006, p. 16).

Monteiro (2001) defende que a formação inicial poderia ser um importante momento na construção dos saberes do futuro profissional, desde que se constituísse como um processo de formação continuada, pois, assim, possibilitaria trocas, sensibilizaria e instrumentalizaria os futuros docentes para diferentes situações que, provavelmente, acabaria se deparando em sua vida profissional. Além disso, a autora alega que o professor é "sujeito do trabalho 
que realiza e não um simples repassador de saberes produzidos por outros" (MONTEIRO, 2001, p. 136).

Assim, uma formação que privilegiasse a experiência pautada na teoria, poderia ser um caminho no sentido de ampliar, e melhorar, a formação oferecida aos licenciandos de História. Com isso, ocorreriam os domínios de diferentes saberes, como os códigos disciplinares dos currículos, prescrito e oculto, das disciplinas que compõem a grade da graduação (TARDIF; LESSARD; LAHAYNE, 1991) e a apropriação da cultura docente.

Cainelli (2008a) afirma que a História Ensinada pertence ao domínio do saber historiográfico e seu estatuto é o mesmo da História Erudita. Por isso, é preciso entender o conhecimento histórico, na perspectiva da investigação histórica, para se ter condições de ensinar história (CAINELLI, 2008b, p. 3). Este pensamento, segundo a autora, não é recente $e$, quando analisamos os currículos propostos desde a implantação do Ensino de História, no século XIX, até os dias atuais, percebemos que desde o início da implantação da disciplina de História ocorreu uma preocupação em relacioná-la com os estudos historiográficos, porém nem sempre o saber histórico, produzido em sala de aula, seguiu o rigor científico exigido pela academia.

A partir das discussões de Gago (2007), podemos inferir que a formação do professor afetaria a forma como ele se relaciona com alunos e conteúdos escolares. Por isso, a autora propôs analisar como isso se daria partindo de uma investigação cuja questão central identificou os perfis conceituais que os professores de História apresentavam em suas narrativas, entendida por ela como uma das faces da consciência histórica. Em suas conclusões, apontou que "os dados do estudo final sugerem existir uma relação entre o perfil da consciência histórica dos participantes e os sentidos de aprendizagem dos alunos." (GAGO, 2007, p. 355). Assim, percebeu que um debate sobre como "operacionalizar as questões referentes à Epistemologia do conhecimento social" era necessário e urgente.

Para Gago (2007, p. 339), esses debates não poderiam ser feitos de maneira unilateral, mas somente num "percurso a ser construído entre professores de História e educadores/formadores de professores de História, entre a escola e o ensino superior, visando o contínuo crescimento profissional de 
forma transformadora".

\section{Conceitos da Educação Histórica utilizados nas narrativas produzidas pelos egressos do Pibid}

O grande desafio do ensino de História, segundo Barca (2012), é "constituir uma ponte gradual, e não um fosso, entre o que os alunos aprendem e o que os historiadores e filósofos da História pensam e produzem". Com isso, a pesquisadora acredita que seria possível

[...] responder às exigências do pensamento científico numa perspectiva de desenvolvimento humano sustentado. A atitude investigativa, portanto, tem de estar solidamente ancorada numa reflexão epistemológica sobre o conhecimento histórico e social. Sem o desenvolvimento consistente de competências de compreensão epistemológica, a eficácia dos procedimentos investigativos ficará irremediavelmente comprometida. (BARCA, 2012, p. 38).

Barca (2012, p. 39) aponta que o volume e a qualidade dos estudos desenvolvidos dentro deste campo teórico podem nos fazer inferir que ele reivindicasse a formação de um estatuto científico específico; para isso, investigou sobre a existência de um objeto principal, que seria as "concepções dos vários tipos de sujeitos que desenvolvem o seu pensamento histórico em vários níveis (com destaque para as ideias de alunos e professores)." Assim, destaca que as pesquisas realizadas dentro do campo teórico da Educação Histórica convergem em

- Princípios educacionais transversais considerados mais adequados na formação para o mundo de hoje, com influência do construtivismo na vertente da aprendizagem situada[...].

- Reflexão epistemológica atualizada sobre conceitos e metodologias fundamentais para a construção de um conhecimento histórico genuíno,

- Conhecimento histórico contextualizado, problematizado e aberto a múltiplas perspectivas.

- Metodologias de análise de dados de natureza qualitativa, intensiva e indutiva (BARCA, 2012, p. 39). 
Em nossa pesquisa não tivemos a pretensão de nos apropriar desse arcabouço metodológico, mas analisar alguns conceitos que são fundamentais para este campo teórico como Aula-oficina, ideias prévias, conceitos substantivos, conceitos de segunda ordem, narrativa e progressão de conhecimentos. Partindo desse pressuposto, em nossa investigação, percebemos que os diferentes produtos, deixados pelos pibidianos participantes do subprojeto 2011-2013, poderiam ser utilizados como fontes em nossa pesquisa, dado que neles é possível verificar a utilização de conceitos relacionados com a Educação Histórica. Percebemos, também, que ao fazer uso dessas categorias em suas atividades, os pibidianos pretendiam oportunizar uma aprendizagem desafiante, criativa e válida, contribuindo para o desenvolvimento de competências cognitivas essenciais para o ensino de História.

O modelo de aula chamado Aula-oficina, um dos pressupostos utilizado para nortear os trabalhos dos pibidianos do subprojeto de História/Uel, surgiu a partir dos estudos de Barca (2013), segundo a autora, organizados em 1999 como parte das aulas que ministrava na Universidade do Minho, região norte de Portugal. A pesquisadora indicou que, nesse modelo, a aula de História deveria ser organizada seguindo alguns passos:

Primeiramente o professor deveria selecionar um conteúdo,
perguntando aos alunos o que eles sabem a respeito e, então,
selecione as fontes históricas pertinentes para a aula. Em seguida,
ele deve orientar os estudantes a analisar os materiais, fazer
inferências e comparações. Todos se envolvem no processo e
produzem conclusões históricas, que podem ser mais ou menos
válidas e mais ou menos próximas às dos historiadores. No
entanto, elas devem sempre ser valorizadas, avaliadas e
reconceitualizadas com a ajuda do educador. Assim, as crianças
tomam consciência do que aprenderam, do que falta saber e do
que mais gostariam de conhecer. A aula-oficina vai contra a
corrente que não se preocupa com o que ensinar e prioriza em
manter o grupo motivado (BARCA, 2013).

Para Barca (2004a, p. 131-132), esse modelo de aula seria uma forma de contrapor-se à aula-conferência, "proposto pelo paradigma tradicional" que se baseava numa "lógica do professor como detentor do verdadeiro conhecimento, cabendo aos alunos [...] receber as mensagens e regurgita-las [...] em testes escritos". A aula-colóquio, modelo que, segundo Barca (2004a, p. 132), busca suas bases na pedagogia por objetivos, apresentou avanços em relação ao 
modelo anterior (aula-conferência) quando sua ação educativa entendia que a aula "para ter alguma eficácia, precisava ser planejada organizada coerentemente para além da preparação dos conteúdos". No entanto, ainda que o conhecimento fosse problematizado, e partilhado, "a atenção continuava a centrar-se na atividade do professor e nos seus materiais de apoio, mantendo-se na sombra o cuidado com ideias prévias dos alunos e consequentemente tarefas cognitivas a desenvolver na aula pelos alunos" (BARCA, 2004a, p. 132).

No modelo da Aula-oficina, por sua vez, o professor é visto como um investigador social a quem caberia "aprender e interpretar o mundo conceptual dos seus alunos, não para de imediato o classificar certo/errado", mas para auxiliá-lo a modificar, de maneira positiva, os conceitos e ideias que os mesmos possuem sobre os temas e conteúdos propostos. Assim o aluno é "visto como agente do seu próprio conhecimento" e as atividades propostas nas aulas deveriam ser "diversificadas e intelectualmente desafiadoras [...] de forma que todos os materiais produzidos pelos alunos, os testes os diálogos fossem produtos a serem avaliados pelos professores." (BARCA, 2004a, p. 134).

Com isso, Barca (2004a, p. 136) defende que, ao planejarem suas aulas, os professores devem ter como foco as competências a serem desenvolvidas e não os conteúdos a serem ensinados. Competências que deveriam contemplar "os domínios da cronologia, conhecimento e compreensão de temas em âmbito e profundidade, interpretação histórica (interpretação de fontes) e comunicação". Os planejamentos das aulas deveriam, portanto, serem feitos de maneira cuidadosa, o que contribuiria para promover uma aprendizagem sistematizada e não apenas comprometida com a aquisição dos conteúdos.

Para Isabel Barca, esse modelo de plano de aula atende alguns princípios de aprendizagem como:

I - É possível que as crianças compreendam a História de uma forma genuína, com algum grau de elaboração, se as tarefas e contextos concretos das situações em que forem apresentados tiverem significado para elas.

II - Os conceitos históricos são compreendidos gradualmente, a partir da relação com os conceitos de senso comum que 0 sujeito experiência. O contexto cultural e as mídias são fontes de conhecimento que devem ser levadas em conta, como ponto de partida para a aprendizagem histórica. 
III - Quando o aluno procura explicações para uma situação do passado à luz da sua própria experiência revela já um esforço de compreensão histórica. Este nível de pensamento poderá ser mais elaborado do que aquele que assenta em frases estereotipadas, desprovidas de sentido humano.

IV - O desenvolvimento do raciocínio histórico processa-se com oscilações e não de uma forma invariante. Tanto as crianças, como adolescentes e adultos poderão pensar de uma forma simplista, em determinadas situações, e de uma forma mais elaborada noutras.

V - Interpretar o passado não significa apenas compreender uma versão acabada da História que é reproduzida no manual ou pelo professor. A interpretação do "contraditório', isto é, da convergência de mensagens, é um princípio que integra o conhecimento histórico genuíno (BARCA, 2004a, p. 139).

Ao caminhar nessa trajetória, Barca (2004a) assinala que a Aula-oficina vai na contramão dos modelos que não se preocupam com o que ensinar, assim como em motivar os alunos. Apoiando-se em Barca (2000), Theobald entende que a dialética do conhecimento histórico, especialmente dos estudantes tem como ponto de partida a explicação provisória que os mesmos davam ao assunto que estavam estudando, e toda elaboração conceitual feita a partir disso tornava-se uma nova explicação provisória, até que uma nova elaboração fosse feita sobre o mesmo assunto (THEOBALD, 2013, p. 3).

Desta forma, considera que apesar de ser uma metodologia de simples aplicação, a Aula-oficina necessitava de muito trabalho de análise, o que evidencia a sua importância para o ensino de História.

Schmidt e Garcia (2006, p. 22) destacam que "a investigação e a análise dos conhecimentos prévios também serviriam de ponto de partida para a seleção das fontes, materiais e problematizações que serão trabalhadas em aula". Com isso, as autoras entendem que a utilização desse recurso é um passo fundamental na construção de uma metodologia de ensino de História que possibilita

[...] dar voz a todos os sujeitos envolvidos na relação ensino e aprendizagem da História - os professores, os alunos e a comunidade - além de envolvê-los no processo de produção do conhecimento, indicando a importância da opção pela pesquisa em colaboração como metodologia a ser assumida nos processos de formação continuada de professores (SCHMIDT; GARCIA, 2006, p. 24). 
Para Ribeiro, Almeida e Gomes (2006, p. 128), os conhecimentos prévios podem ser considerados como importante variável no processo de aprendizagem, pois o seu conhecimento, por parte do professor, resultaria em uma possibilidade de melhorias na "atenção, percepção, compreensão e organização da nova informação" a ensinar. Assim, o conhecimento prévio do sujeito seria a base sobre a qual se construiria uma efetiva aprendizagem.

No entanto, para Schmidt e Garcia (2006), essa categoria não pode ser analisada apenas como os conteúdos que os estudantes conhecem, mas sua análise deve ter o olhar atencioso do professor, a quem caberia oportunizar aos alunos, a partir da aula-oficina

A compreensão contextualizada do passado, com base na evidência disponível, e pelo desenvolvimento de uma orientação temporal que se traduza na interiorização de relações entre o passado compreendido, o presente problematizado e o futuro perspectivado (BARCA, 2004b, p. 134).

Com isso, como um dos passos da Aula Oficina, "a investigação e a análise dos conhecimentos prévios também serviriam de ponto de partida para a seleção das fontes, materiais e problematizações que seriam trabalhadas em aula" (SCHMIDT; GARCIA, 2006, p. 23). Sobre o uso de fontes como um dos passos da Aula oficina, que seria norteado pelos dados obtidos com a investigação dos conhecimentos prévios dos alunos, Barca (2013) aponta ser importante "não só garantir a variedade de fontes, como considerar a perspectiva de cada uma e planejar momentos diferentes para estudá-las". Assim, ao oferecer para os alunos o estudo com fontes que apresentassem perspectivas diferentes sobre um personagem ou um fato histórico, seria mais significativo a análise ser feita em momentos diferentes para, a partir disso, buscar as semelhanças e diferenças oportunizando, aos alunos, perceber os distintos pontos de vista.

Sobre o processo de construção do conhecimento, Cainelli (2012) afirma que a Educação Histórica apresenta a ideia de divisão dos conceitos históricos em dois tipos: Conceitos substantivos e Conceitos de segunda ordem. A partir das ideias de Lee (2001), a pesquisadora define que

Por conceitos substantivos entende-se os conteúdos da História, por exemplo o conceito de industrialização, renascimento, 
revolução. Enquanto conceitos de segunda ordem: são conceitos que estão envolvidos em qualquer que seja o conteúdo a ser aprendido. Entre os conceitos de segunda ordem, podemos citar continuidade, progresso, desenvolvimento, evolução, época enfim que se referem à natureza da História, como explicação, interpretação, compreensão (CAINELLI, 2012, p. 175).

Além disso, Cainelli (2012, p. 175) aponta que outros temas poderiam ser entendidos como conceitos de segunda ordem, pois a narrativa, evidência, inferência, imaginação e explicação histórica ao serem associados ao conteúdo/conceitos substantivos, poderiam oportunizar, ao aluno, a compreensão do conhecimento histórico. Para a pesquisadora, é preciso que os professores da Educação Básica, ao construírem suas aulas, levem em

[...] consideração as ideias de segunda ordem, ou seja, da natureza da história, pois isso seria mais significativo que as ideias substantivas, pois se referem aos procedimentos necessários para se dialogar com os conhecimentos históricos, proporcionando desta forma conferem sentido aos conceitos substantivos [...] (CAINELLI, 2012, p. 176).

Sobre o conceito de narrativa, uma categoria importante nas atividades e pesquisas desenvolvidas no campo da Educação Histórica, Rüsen (2010, p. 97) afirma que a narrativa histórica é estabelecida a partir de três qualidades. A primeira é a ligação que a narrativa histórica tem com o ambiente da memória, o que oportuniza o estabelecimento de uma relação presente-passado-futuro, na qual a mobilização das memórias do passado daria significado ao tempo presente e criaria uma expectativa de futuro.

A segunda qualidade, para Rüsen (2010), seria a capacidade de a narrativa histórica organizar essas três dimensões do tempo através da ideia de continuidade. Com isso, a experiência do passado teria relevância para a vida presente. A terceira qualidade seria a capacidade da narrativa histórica em estabelecer a identidade entre quem a escreve e os leitores. Nesse sentido, Rüsen (2010, p. 95) afirma que a "narrativa histórica: é um sistema de operações mentais que define o campo da consciência histórica".

Rüsen (2010, p. 98) acredita que a narrativa histórica tem a função de "orientar a vida prática no tempo, mobilizando a memória da experiência temporal, por meio do desenvolvimento de um conceito de continuidade e pela 
estabilização da identidade". Segundo o autor, esse processo poderia ser realizado de quatro maneiras: Narrativa tradicional, exemplar, crítica e genética.

Ao se apropriar desse conceito, pesquisadores do campo da Educação Histórica, como Gevaerd (2009), entenderam que a narrativa é uma maneira de ensinar e aprender história, pois

\begin{abstract}
Narrar histórias em aulas de história é uma forma de relatar o passado e, consequentemente, interpretar este passado e, por isso, as narrativas são um componente significativo do pensamento histórico e uma ferramenta central no ensino e na aprendizagem em história, podendo ser considerada como fundamental nessas aulas (GEVAERD, 2009, p. 67).
\end{abstract}

Para Barca (2004b) é na narrativa histórica que se materializa a aprendizagem histórica. Nesse processo, analisamos alguns conceitos que são partes das ideias sobre como deveria ocorrer o ensino de História. Nesse sentido, buscamos identificar como os pibidianos se apropriaram dos conceitos da Educação Histórica, mais especificamente da Aula-oficina, e a aplicaram em suas experiências no projeto e, posteriormente, como professores da Educação Básica.

\title{
2. Licenciandos e licenciados em História
}

Nossa investigação foi realizada a partir de relatórios entregues pelos pibidianos, nos anos de 2011 e 2012, os quais revelaram acreditar na possibilidade de exercer a docência a partir dos pressupostos da Educação Histórica, em especial, o modelo de Aula-oficina. A partir desses dados, montamos um questionário que tinha como objetivo identificar quem era nosso sujeito, e como ele percebia as ideias presentes nas pesquisas da Educação Histórica que deram sustentação as atividades de docência durante sua participação no PIBID.

Neste artigo, trabalharemos com as questões do estudo principal que nos permitiu perceber o uso da Educação Histórica na preparação das aulas e atividades como professores. Nas narrativas dos pibidianos, o destaque foi para o uso de fontes como meio para que o aluno construísse seus conhecimentos 
históricos. De certa forma, o uso de fontes e documentos mostrou-se como um dos elementos da Educação Histórica mais utilizados pelos pibidianos e citados em documentos consultados em nossa pesquisa. Assim, podemos inferir que, na percepção desses sujeitos, o Ensino de História pressupõe o envolvimento dos alunos e o uso de fontes como elemento fundamental e não apenas como ilustração das narrativas contadas pelos professores.

No gráfico abaixo, visualizamos as ideias que apareceram como exemplos de apropriação desse campo teórico pelos pibidianos em suas aulas:

Figura 1- Usos de conceitos da Educação Histórica pelos pibidianos

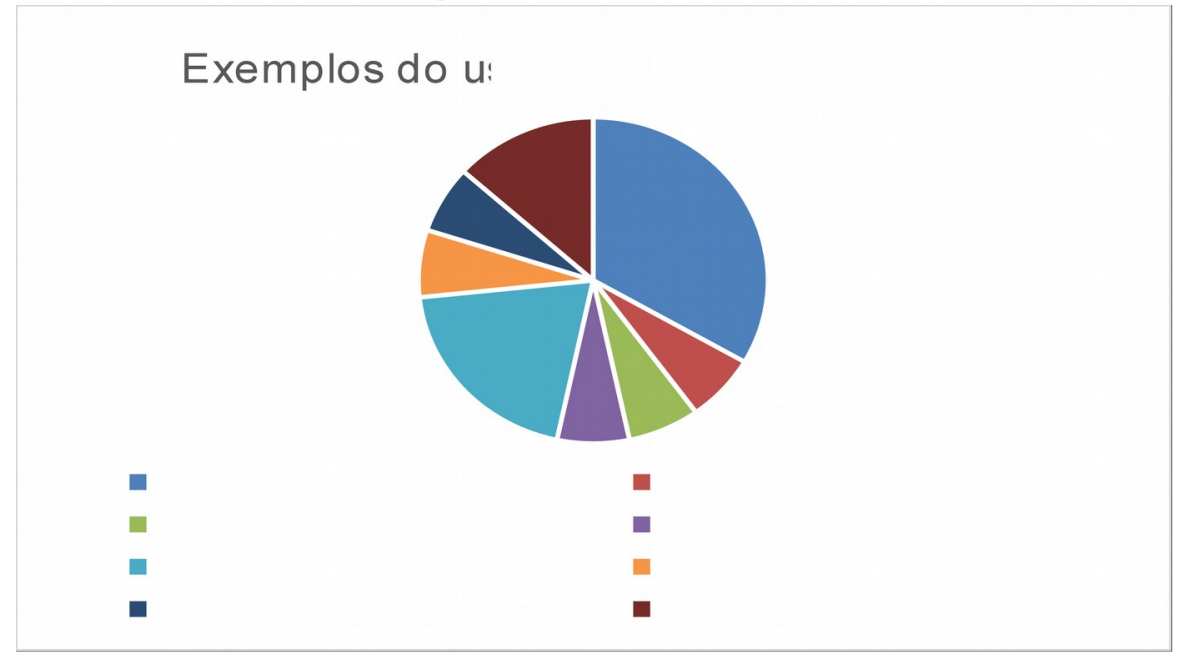

Fonte: Os autores.

Ao usar as ideias da Educação Histórica, os pibidianos afirmam ter um novo olhar sobre o Ensino de História, assim como buscavam fazer da aprendizagem dos conteúdos históricos um conhecimento que fosse significativo para os alunos da Educação Básica, onde o usassem em sua vida prática. Todavia, o estudo principal não nos forneceu dados mais precisos sobre o que, efetivamente, ocorria nas aulas desses sujeitos. Um dos pibidianos nos indica que o ambiente escolar, com suas normas e exigências, nem sempre possibilitava a utilização de fontes como maneira de levar os alunos a construírem suas ideias acerca dos conteúdos. Por isso, solicitamos a cinco pibidianos uma conversa, para que, por meio de alguns questionamentos, pudéssemos perceber, com mais clareza, como se dava o uso desse campo teórico. 


\section{Conversas com pibidianos/professores de história: a Aula-oficina como metodologia em sala de aula}

Nas entrevistas com os pibidianos, procuramos investigar como a formação recebida, durante o PIBID, se concretizou em suas ações docentes na perspectiva da Educação Histórica.

Entrevistamos todos pibidianos que no estudo principal tinham declarado a atuação como professor, por acreditarmos haver dados relevantes sobre o uso das ideias da Educação Histórica por esses sujeitos. Nossa entrevista teve como guia um roteiro com oito perguntas que procuravam identificar as apropriações de alguns conceitos como o uso da Aula-oficina, com seus passos e encaminhamentos, as ideias de progressão dos níveis de consciência Histórica e a forma de utilização da Educação Histórica.

Os pibidianos entrevistados foram Gabriela, João, Denise, Guilherme e Helen $^{5}$. A partir das entrevistas, podemos observar que o uso de fontes nas aulas de História constitui-se no encaminhamento mais efetivo da Educação Histórica e, para todos, o que impede a utilização das ideias e pressupostos deste campo teórico, de forma mais consolidada, está no número excessivo de alunos em sala de aula, assim como o pouco tempo disponível para os planejamentos das mesmas.

Guiamos nossa conversa, inicialmente, questionando-os como, efetivamente, utilizaram as ideias da Educação Histórica para lecionar sua aula de História. Observamos que, para estes sujeitos, o uso de fontes e a investigação constituíram-se nas ideias mais presentes em suas aulas, e evocavam o que aprenderam durante o período em que estiveram no PIBID. No entanto, todos pontuaram que as dificuldades encontradas, como turmas numerosas e a jornada de trabalho, impediam uma aplicação mais rotineira dos pressupostos da Educação Histórica. Sobre isso, afirmaram

A teoria ela não dá conta da prática, nunca, você que está dentro da sala de aula você sabe disso. Igual aqui em Minas, um exemplo, tem quarenta alunos, quarenta alunos que pelo menos $20 \%$ chega sem saber ler, chega sem saber escrever. E como que

5 Todos nomes fictícios. 
você dá aula de história, que você envolve uma coisa mais profunda, se eles não sabem nem interpretar um texto? Primeiro ponto. Segundo ponto, questão da disciplina, aqui eu perco pelo menos 20 minutos de aula para a sala ficar quieta, de quinze a vinte minutos. Porque é uma indisciplina tão grande, mas tão grande, aí no Paraná eu tinha tido sala assim, indisciplinada, mas aqui eu tenho sala com 44 alunos, Bete. ${ }^{6}$

Sim, eu me vejo aplicando isso, só que essa aplicação é diferente da forma como se fazia no PIBID, não é? Porque no PIBID justamente nós estávamos aprendendo a fazer isso, então acho que era necessário pensar, refletir, preparar uma aula, demandava um tempo, não é? Uma pesquisa muito grande. E isso no cotidiano da sala de aula, até isso que eu disse, não é, no meu questionário, algo que se torna um pouco difícil, não é? Mas ainda assim o que eu queria dizer que essa experiência que o PIBID proporcionou de ter colocado em prática, não é, a visão da educação histórica, as propostas da educação histórica, isso transformou a visão que eu tenho, que eu tinha sobre o ensino de história, que era basicamente construída a partir da minha própria experiência como aluno em história. Isso transformou e a impressão que eu tenho que isso realmente guia, realmente me imbui de uma percepção, de uma visão muito clara do que é ensinar história.?

'Como podemos perceber, a realidade encontrada nas escolas onde atuaram e atuam como professores, de certa forma, impôs dificuldades para realização das atividades, no entanto há uma clara percepção da professora de que o pressuposto da Educação Histórica mudou a forma dela entender o que é ensinar História, e a metodologia da Aula-oficina pode servir de guia para o ensino de História.

A segunda questão que fizemos tinha o intuito de investigar quais outras dificuldades poderiam enfrentar para, efetivamente, utilizar este campo teórico em suas aulas. Sobre isso, os cinco entrevistados apontaram que a falta de recursos, como meios de multimídia e acesso a copiadoras, acabaram impelindoos, como professores, a utilizar os livros didáticos. Ainda que apontassem as deficiências deste recurso, afirmavam que o livro impedia a aula de se resumir ao quadro de giz e exposições orais.

Aqui não tem nem estrutura, aí no Paraná, ainda tem a tv Pendrive ${ }^{8}$, que ela ajuda muito a gente, ajudava. Me ajudava muito, se eu quisesse levar uma imagem, um trecho de um filme,

6 Denise (2017). Entrevista II concedida à Elizabete Cristina de Souza Tomazini em março de 2017. 1 arquivo. Mp3 (60 minutos).

7 Guilherme (2017). Entrevista II concedida à Elizabete Cristina de Souza Tomazini em março de 2017. 1 arquivo. Mp3 (55 minutos). 
uma música, isso auxiliava, aqui não tem nem isso. É uma disputa para usar a sala de vídeo que eu nem entro na disputa. Por que é uma sala de vídeo na escola e todos procuram para usar, então as vezes a gente acaba caindo no modo mais tradicional de giz e lousa mesmo por que é o que contenta aquilo ali no momento. ${ }^{9}$

Outra dificuldade que levantaram foi o desinteresse dos alunos:

A história do período da noite já era mais difícil, lá eu fiquei de finalzinho de outubro até meados de novembro, deu mais ou menos um mês, também era uma substituição. Só que o período noturno é muito complicado, primeiro não havia material didático na escola, os alunos faltavam muito, não é? Uma turma de trinta, quarenta, vinham cinco, três, quatro. Então assim, não havia neles uma vontade mesmo, até porque segundo eles próprios diziam, os professores já faziam isso. E era meio que verdade na sala de professores a gente ouvia que eles estavam ali só para fazer bagunça e fumar maconha, não é, e eles fumavam mesmo na porta da sala. Só que era muito difícil, então assim, não havia como você trabalhar, assim, então assim foi ali o método mais tradicional, mesmo preso no conteúdo do livro poucos participavam. Então assim, eu tive ali acho que seis turmas, muita falta de aluno, muito falta de professores, então eles matavam aula. No final até eles me convidaram para a ir para a formatura deles, eles gostaram até do jeito de dar aula. Não fui, não é, não deu tempo, aí a professora voltou. Então eu percebi, nesses dois momentos, é muito diferente, e é uma coisa que infelizmente nossa formação acadêmica não nos prepara. ${ }^{10}$

A terceira questão que fizemos procurou investigar como os futuros professores, agora formados, entendiam a formação recebida na Universidade, mais precisamente nas disciplinas de Metodologia do Ensino de História. Nesse sentido, quatro pibidianos apontaram a importância da formação acadêmica fazendo referência especificamente ao PIBID para a sua atuação docente. Apenas João (2017) mostrou-se mais reticente e criticou, duramente, a formação recebida na Universidade

[...] a formação no ensino de história, por ser licenciatura, é muito aquém ainda. Falta muita prática, falta ir mais, falta conhecer realidades de horários diferentes. Então eu fazia noturno quando

8 TV Pendrive é a forma dos professores se referirem a televisão que existe em todas as salas de aula no Paraná onde é possível trabalhar com documentos a partir da utilização de pendrive.

9 Denise (2017). Entrevista II concedida à Elizabete Cristina de Souza Tomazini em março de 2017. 1 arquivo. Mp3 (60 minutos).

10 João (2017). Entrevista II concedida à Elizabete Cristina de Souza Tomazini em março de 2017. 1 arquivo. Mp3 (55 minutos). 
eu estudei, e eu nunca fui numa escola no noturno, eu nunca estudei no noturno, a minha primeira experiência com o noturno foi essa, e eu já sabia de todo o contexto, não é? Mas eu nunca tinha trabalhado no noturno. Então não é preparado, a gente não tem essa preparação nem pela faculdade [...].

\title{
Assim como criticou, também, o campo teórico que o formou no PIBID
}

\begin{abstract}
Porque ele ensina aonde a gente tem ideal, não é, aonde o educador vai ser o mediador. No Brasil ainda estamos longe, até porque a nossa formação não é assim, nós que saímos das faculdades, e dos alunos também falta para eles muito isso. Acho que lá em Portugal, na escola onde eles pensaram nisso, eles tentam colocar numa linha muito próxima mais de uma qualidade. $E$ nós, no ensino profissionalizante agora percebemos que a qualidade não é o ponto para o Brasil. ${ }^{11}$
\end{abstract}

Nas questões cinco, seis e sete investigamos três conceitos que são referência para Educação Histórica: Consciência Histórica, a história como estudo que parte das demandas do presente para nortear as investigações no passado e a produção de conhecimento durante as aulas de História. Sobre a percepção nas narrativas de uma Consciência Histórica, esta não pareceu ser uma ideia clara para os entrevistados. Primeiro, porque a maioria dos pibidianos não pareceu identificar mudanças, ou mesmo as ideias iniciais, nos alunos na Educação Básica sobre as temáticas que estão estudando.

Eu acredito que consigo perceber isso em alguns alunos, não digo que isso aconteceu com todos. Vai ser aquela coisa, muda de turma para turma, tem turmas que parece que o trabalho às vezes fica enterrado, o trabalho encontra certas dificuldades, não é? Então isso é algo que eu não consegui medir, de fato, então objetivamente até, não é? Eu percebo que vendo alguns resultados de prova, vendo algumas, não é, resultados de avaliações que a gente vai percebendo, que alguns alunos vão desenvolvendo uma sensibilidade mesmo de olhar para o passado, perceber as alteridades, relações de consequência, de causa, não é? ${ }^{12}$

Antes da gente pensar nisso, Bete, tem que pensar no nível de interesse do aluno, sabe? Porque às vezes é aquilo que eu te falei, é a porcentagem de aluno que não quer nada. Em cima disso aí, e aí em cima desses que a gente mais tenta trabalhar, não é, que a gente quer, lógico que a gente perde as forças físicas, mentais em

11 João(2017). Entrevista II concedida à Elizabete Cristina de Souza Tomazini em março de 2017. 1 arquivo. Mp3 (55 minutos).

12 Guilherme (2017). Entrevista concedida à Elizabete Cristina de Souza Tomazini em março de 2017. 4 arquivos. Mp3 (72 minutos). 
cima desses, não é? Que você tenta, que você tenta, que você tenta, e que você vai lutando, não é? Então antes de pensar nisso o quê que está sendo, que tipo de consenso que está sendo, não é, construído, enfim, que está sendo identificado na sala de aula? Tem que pensar nisso, sabe? Nesses alunos que, essa porcentagem que não quer nada com nada, que você não consegue, não é? E aí tem uns que, tem uns que chega assim já supercrítico, que está querendo ver a aula, que está querendo entender, não é? Que você consegue ainda trabalhar de outra forma mais. E tem aqueles que já chegam com os valores familiares meio, então eles já chegam moldadinhos assim, você não consegue ultrapassar aquela barreira, não é? ${ }^{13}$

Nesse relato, percebemos que a professora indica um afastamento da teoria, porém consegue identificar três categorias de alunos nas turmas por ela atendidas na Educação Básica, o que acaba impactando nas ações criadas para trabalhar esse olhar, sobre um grupo que se mostra multiperspectivado em seu pensamento a respeito dos conteúdos, contexto que acaba sendo um embate para essa jovem professora.

O estudo da História a partir das questões do presente, mostrou-se outra ideia das quais os pibidianos tentam se apropriar, mas muitas vezes não o fazem de maneira muito clara. João destaca que o uso desta ideia se dá quando, na escola de curso técnico na qual atua, utilizam situações para serem resolvidas. Para este pibidiano, e agora professor, um dos grandes desafios do próprio curso de História é dar sentido ao que se estuda nos cursos de licenciatura:

[...] acho que a teoria precisa ter para dar base e aí você poder entrar com uma qualidade, porque não adianta você ir lá na escola só por ir, qualidade, você tem que fazer diferença. Mas que pudesse trazer cada vez mais as práticas nas próprias escolas, mas não que jogasse responsabilidades para os próprios educadores das escolas, até porque não é por aí. Eu acho que deveria ter um formato que tinha que é o de diálogo, de conversa, não é? O professor universitário mais próximo. Hoje eu vejo professor universitário, e aí é uma crítica que eu tenho muito forte, ele vive no mundo da ideia, no mundo do projeto dele, no mundo do estudo dele, e o que está em volta pouco ele se importa. Então assim, eu tenho uma visão muito crítica disso porque isso me pareceu praticamente grande parte da minha formação. Então assim, quando fala: "Vamos estudar aqui história do Brasil na época da ditadura", foi aonde eu estudei o meu mestrado. Foi horrível, as minhas aulas que eu tive, foi péssimo, na época, foi horrível. Era horrível, era ler texto e discutir texto,

13 Denise (2017). Entrevista concedida à Elizabete Cristina de Souza Tomazini em março de 2017. 2 arquivos. Mp3 (55 minutos). 
isso não é prática. Ler o texto para? Qual que é o objetivo de eu ler o texto? É ter alguma coisa. ${ }^{14}$

No que se refere às escolas enquanto espaços de produção de conhecimento, os entrevistados recorrem às memórias das atividades do projeto como exemplos de sua ocorrência. No entanto, não parecem buscar isso, de uma maneira mais explícita, em suas atividades como professores.

\section{Considerações finais}

Neste artigo apresentamos parte das investigações sobre as experiências na formação de professores de História, dentro do PIBID, da Universidade Estadual de Londrina, e quais transformações este projeto vem provocando neste processo formativo docente. Os dados que temos apontaram que a presença deste programa, na Universidade e escolas da Educação Básica, tem produzido um debate sobre como deveria ser a formação dos futuros professores. Assim, o grupo de pibidianos, aqui analisados, mostrou que associar a teoria com a prática pode ser um caminho para superar essa dicotomia.

As entrevistas revelaram que o embate entre a realidade das escolas, as salas de aula e os saberes apreendidos nas universidades, ideia apresentada por Barca (2013), mostrou-se crucial, uma vez que entre os sujeitos foram apresentados os obstáculos causados pelo número excessivo de alunos e as dificuldades de alguns profissionais em aceitar novas metodologias com ideias sobre como deveriam ser organizadas as aulas não só de História, como de outras disciplinas escolares. Outro ponto percebido foi que o estudo de teorias embasadoras das práticas docentes não se tornou rotina na vida profissional destes sujeitos.

No que tange aos usos da Educação Histórica e da Aula-oficina como metodologia de sala de aula, percebemos que muitas de suas características são utilizadas pelos professores participantes da pesquisa. Observamos uma apropriação de conceitos como conhecimentos prévios, utilização de fontes

14 João/2017. Entrevista II concedida à Elizabete Cristina de Souza Tomazini em março de 2017. 1 arquivo. Mp3 (55 minutos). 
multiperspectivadas e a ideia de que o professor não pode se configurar em, apenas, um repassador de conteúdos.

Por fim, concluímos que a formação inicial de professores, oferecida pelo PIBID, pode impactar, positivamente, na atuação desses sujeitos, quando seguem carreira como profissionais da Educação Básica ou optam por continuar no mundo acadêmico. Nesse sentido, a experiência oportunizada pelo subprojeto de História da UEL 2011-2013, que pautou seus encaminhamentos a partir das pesquisas da Educação Histórica, corroborou as ideias de Barca (2001), quando esta afirma ser preciso repensar a formação oferecida aos futuros professores de História, e isso deve ser um movimento contínuo e oportunizado a outros licenciandos.

\section{Referências}

BARCA, Isabel. (Org.). Para uma educação histórica de qualidade. Braga: Universidade do Minho, 2004b.

BARCA, Isabel. Aula oficina: do projeto à avaliação. In: JORNADA DE EDUCAÇÃO HISTÓRICA, 4., 2004, Braga. Anais... Braga: Centro de Investigação em Educação (CIED), Universidade do Minho, 2004a, p. 131-144.

BARCA, Isabel. Educação histórica: uma nova área de investigação. Revista da Faculdade de Letras e História, Porto, n. 2, p. 13-21, 2001.

BARCA, Isabel. Ensinar história de modo linear faz com que os alunos se lembrem só dos marcos cronológicos. Revista Nova Escola, São Paulo, ed. 260, mar. 2013. Entrevista concedida a Bruna Nicolielo.

BARCA, Isabel. Ideias chave para a educação histórica: uma busca de (inter) identidades. História Revista, Goiânia, v. 17, n. 1, 2012, p. 37- 51. Disponível em: <https://www.revistas.ufg.br/historia/article/view/21683>. Acesso em: 10 jan. 2017.

BARCA, Isabel. O papel da educação histórica no desenvolvimento social. In CAINELLI, Marlene; SCHMIDT, Maria Auxiliadora (Org.). Educação história: teoria e pesquisa. Ijuí: Ed. da UNIJUI, 2011.

CAIMI, Flavia Eloisa. Por que os alunos (não) aprendem História? Reflexões sobre ensino, aprendizagem e formação de professores de História. Revista Tempo, Rio de Janeiro, v. 11, n. 21, p. 17-32, 2007. 
CAINELLI, Marlene. A Escrita da História e os Conteúdos Ensinados na Disciplina de História no Ensino Fundamental. Educação e Filosofia, Uberlândia, v. 26, n. 51, p. 163-184, 2012.

CAINELLI, Marlene. Educação histórica: ensinando e aprendendo história no ensino fundamental: texto mesa redonda. In: ENCONTRO NACIONAL DOS PESQUISADORES DO ENSINO DE HISTÓRIA. Metodologias e Novos Horizontes, 8., 2008, São Paulo. Anais... São Paulo: Faculdade de Educação da Universidade de São Paulo, 2008a.

CAINELLI, Marlene. Os saberes docentes de futuros professores de história: a especificidade do conceito de tempo. Currículo sem Fronteiras, Porto, v. 8, n. 2, p.134-147, jul./dez. 2008b.

CAINELLI, Marlene; SCHMIDT, Maria Auxiliadora (Org.). Educação história: teoria e pesquisa. Ijuí: UNIJUI, 2011.

GAGO, Marília. Consciência histórica e narrativa: concepções de professores. 2007. Tese (Doutorado em Educação) - Universidade do Minho, Braga.

GEVAERD, Rosi Terezinha Ferrarini. A narrativa histórica como uma maneira de ensinar e aprender história: o caso da história do Paraná. 2009. Tese (Doutorado em Educação) - Universidade Federal do Paraná, Curitiba.

LEE, Peter. Em direção a um conceito de literacia histórica. Educar em Revista, Curitiba, n. esp. p. 1-14, 2006. Disponível em: <http://www.scielo.br/scielo.php? script $=$ sci_arttext\&pid=S0104-40602006000400008\&lng $=$ en\&nrm $=$ iso $>$. Acesso em: 10 mar. 2016.

LEE, Peter. Progressão da compreensão dos alunos em História. In: BARCA, Isabel (Org.). Perspectivas em Educação Histórica. Braga: Universidade do Minho, 2001, p. 13-27.

MONTEIRO. A. A prática de ensino e a formação inicial de professores. 2001. Disponível em:

<http://www.educacaopublica.rj.gov.br/biblioteca/educacao/0032a.html>. Acesso em: ago. 2016.

RIBEIRO, Iolanda S.; ALMEIDA, Leandro S.; GOMES, Carlos. Conhecimentos prévios, sucesso escolar e trajectórias de aprendizagem: do $1^{\circ}$ para o 20 ciclo do ensino básico. Avaliação Psicológica, Porto Alegre, v. 5, n. 2, p. 127-133, dez. 2006. Disponível em: <http://pepsic.bvsalud.org/scielo.php? script $=$ sci_arttext\&pid=S1677-04712006000200002\&lng=pt\&nrm $=$ iso $>$. Acesso em: 2 mar. 2017.

RÜSEN, Jörn. Narrativa histórica: fundamentos, tipos, razão. In: SCHMIDT, Maria Auxiliadora (Org.). Jörn Rüsen e o ensino de História. Curitiba: Ed. da UR, 2010, p. 93-108.

SCHMIDT, Maria Auxiliadora; GARCIA, Tânia Maria Braga. Pesquisas em Educação Histórica: algumas experiências. Educar, Curitiba, n. esp., p. 11-31, 2006. 
TARDIF, Maurice; LESSARD, Claude; LAHAYE, Louise. Os professores face ao saber: esboço de uma problemática do saber docente. Teoria e Educação, Porto Alegre, v. 4, p. 215-233, 1991.

THEOBALD, Henrique Rodolfo. Investigação de conhecimentos prévios no ensino de história. Fóruns Contemporâneos de Ensino de História no Brasil (on-line), Campinas, 2013. Disponível em:

<http://ojs.fe.unicamp.br/index.php/FEH/article/view/5231/4174>. Acesso em: 10 jan. 2017.

Recebido em 12 de setembro de 2017 Aprovado em 09 de janeiro de 2018 